\title{
Crystal structure of a $\boldsymbol{\gamma}$-herpesvirus cyclin-cdk complex
}

\section{G.L.Card ${ }^{1}$, P.Knowles, H.Laman ${ }^{2}$, N.Jones ${ }^{2,3}$ and N.Q.McDonald ${ }^{4,5}$}

Structural Biology and ${ }^{2}$ Gene Expression Laboratories, Imperial Cancer Research Fund, 44 Lincoln's Inn Fields, Holborn, London WC2A 3PX and ${ }^{4}$ Department of Crystallography, Birkbeck College, Malet Street, London WC1E 7HX, UK

${ }^{1}$ Present address: Laboratory of Structural Biology, University of Auckland, Auckland, New Zealand

${ }^{3}$ Present address: Paterson Institute for Cancer Research, Christie Hospital, Manchester M20 9BX, UK

${ }^{5}$ Corresponding author

e-mail: mcdonald@icrf.icnet.uk

Several $\boldsymbol{\gamma}$-herpesviruses encode proteins related to the mammalian cyclins, regulatory subunits of cyclindependent kinases (cdks) essential for cell cycle progression. We report a $2.5 \AA$ crystal structure of a full-length oncogenic viral cyclin from $\gamma$-herpesvirus 68 complexed with cdk2. The viral cyclin binds cdk2 with an orientation different from cyclin $\mathrm{A}$ and makes several novel interactions at the interface, yet it activates cdk2 by triggering conformational changes similar to cyclin A. Sequences within the viral cyclin $\mathrm{N}$-terminus lock part of the cdk2 T-loop within the core of the complex. These sequences and others are conserved amongst the viral and cellular D-type cyclins, suggesting that this structure has wider implications for other cyclin-cdk complexes. The observed resistance of this viral cyclin-cdk complex to inhibition by the p27 ${ }^{K i p}$ cdk inhibitor is explained by sequence and conformational variation in the cyclin

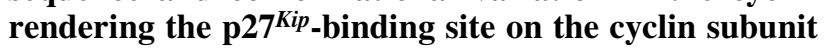
non-functional.

Keywords: cyclin/cyclin-dependent kinase/herpesvirus/ $\mathrm{p} 27^{\text {Kip }} /$ structure

\section{Introduction}

Progression through the mammalian cell cycle is controlled by distinct cyclin-dependent protein kinases whose catalytic activities are regulated by a variety of mechanisms (Morgan, 1995; Pines, 1999). These serine/threonine kinases consist of two subunits: a cyclin protein and a cyclin-dependent kinase (cdk) (Morgan, 1997). Members of the cyclin family bind to and activate specific cdk isozymes and their relative abundance varies during the cell cycle, leading to the periodic activation and inactivation of different cdks (Morgan, 1997). Cdk phosphorylation and levels of cdk inhibitors (CKIs) also affect cdk catalytic activity (Pines, 1999). One well studied cell cycle transition in mammalian cells is the mitogen-dependent entry into S-phase (DNA synthesis), which requires the coordinated activation of cyclin D-cdk4, cyclin D-cdk6 and cyclin E-cdk2 complexes (Sherr, 1994, 1995). Deregulation of the cyclin D-dependent kinases and their downstream targets has frequently been associated with many forms of cancer, underlining the importance of this pathway (Palmero and Peters, 1996; Sherr, 1996). In addition to their catalytic role as protein kinases, specific cyclin-cdk complexes have also been proposed to have non-catalytic roles. The cyclin D-cdk4 and cyclin D-cdk6 holoenzymes phosphorylate the retinoblastoma protein $\mathrm{pRb}$ but also sequester the cdk inhibitors $\mathrm{p} 21^{\text {Cip/WAF }}$ and p27 Kip, which otherwise block cyclin A-cdk2 and cyclin E-cdk2 kinase activity necessary for S-phase entry (reviewed in Sherr and Roberts, 1999).

Cyclin homologues have been identified within the genomes of several $\gamma$-herpesviridae associated with neoplastic disorders, these include herpesvirus saimiri (HSV) (Albrecht et al., 1992; Jung et al., 1994), Kaposi's sarcoma-associated herpesvirus (KSHV/HHV8) (Chang et al., 1996; Russo et al., 1996a) and murine $\gamma$-herpesvirus 68 (Virgin et al., 1997). Herein these viral cyclins will be referred to as V-, K- and M-cyclins, respectively. The viral cyclins are most closely related to the mammalian D-type cyclins, and $\mathrm{K}$ - and $\mathrm{V}$-cyclin have been shown to form active complexes with cdk6 (Jung et al., 1994; Chang et al., 1996; Godden-Kent et al., 1997; Li et al., 1997). Cdk6 bound by K-cyclin exhibits potent activity towards an extended range of substrates including histone $\mathrm{H} 1$ and p27 Kip (Godden-Kent et al., 1997; Ellis et al., 1999; Mann et al., 1999). In addition, the K-cyclin-cdk6 and V-cyclincdk6 complexes are resistant to the $\mathrm{p} 16^{\text {Inka }}$ and $\mathrm{p} 21^{C i p / W A F} /$ p27 ${ }^{\text {Kip }}$ CKIs and thereby overcome constraints to cell cycle progression mediated by their inhibitors (Swanton et al., 1997). The ability of these viral cyclins to deregulate the cell cycle may provide a cellular environment conducive to viral replication, although their precise role in oncogenicity is not clear (reviewed in Laman et al., 2000).

Structural analyses of a fragment of cyclin A bound to cdk2 have revealed the molecular basis for the partial and full catalytic activation of cdk2 (Jeffrey et al., 1995; Russo et al., 1996b). Cyclin A associates with its catalytic partner cdk2 through a conserved region of $\sim 150$ amino acids known as the cyclin box (Brown et al., 1995; Jeffrey et al., 1995). In the presence of cyclin A, two regions of particular importance, the PSTAIRE helix and the T-loop bearing the activating phosphorylation site at Thr160, undergo a dramatic conformational change to influence ATP coordination and the proper formation of a substratebinding cleft (Jeffrey et al., 1995; Russo et al., 1996b). Further studies on a ternary complex of a p27 $7^{\text {ip }}$ peptide bound to cdk2 and a cyclin A fragment defined two independent p $27^{\mathrm{Kip}}$-binding sites, one within cyclin $\mathrm{A}$ and a second within the cdk2 ATP-binding pocket (Russo et al., 1996c). p27 ${ }^{\text {Kip }}$ directly inhibits cyclin A-cdk2 by mimicking the adenosine moiety of ATP and making similar 
contacts to cdk residues within the ATP-binding site (Russo et al., 1996c). The structures of two further cyclins, cyclin $\mathrm{H}$ and $\mathrm{V}$-cyclin, have been determined in their unbound form, demonstrating that all three cyclins have similar three-dimensional folds despite their limited sequence similarity (Brown et al., 1995; Kim et al., 1996; Andersen et al., 1997; Schulze-Gahmen et al., 1999). As part of a study to understand the biochemical and structural properties of viral cyclins, we have determined the structure of the cyclin from $\gamma$-herpesvirus 68 bound to cdk2. We describe novel features of the viral cyclin-cdk 2 interaction when compared with the structure of cyclin A-cdk2 and discuss the functional implications for cdk recognition and regulation.

\section{Results}

We have focused on the cyclin from $\gamma$-herpesvirus 68 as a model cyclin to understand the interaction between virusderived cyclins and the mammalian cdk enzymes. We first determined which cdk subunit was bound by M-cyclin. As shown by co-immunoprecipitation experiments using FLAG-tagged M-cyclin, we demonstrated that M-cyclin binds to cdk2 in vivo rather than the canonical D-type cdkbinding partners cdk4 and cdk6 (Figure 1A). However, the closely related viral cyclin, K-cyclin, has been shown to associate with and activate cdk2, cdk4 and cdk6 (Figure 1A) (Godden-Kent et al., 1997; Li et al., 1997; Mann et al., 1999).

One of the striking features of V-cyclin-cdk6 and $\mathrm{K}$-cyclin-cdk6 complexes is their ability to evade inhibition by $\mathrm{p} 21^{\text {Cip/WAF }}$ and $\mathrm{p} 27^{\text {Kip }}$. This is due to the lack of stable interaction between these cyclin-cdk complexes and CKIs. We assessed the degree of resistance of M-cyclin-cdk2 complexes to inhibition by $\mathrm{p} 27^{\text {Kip }}$. As shown in Figure 1B, M-cyclin-cdk2 was at least an order of magnitude less sensitive to inhibition by $\mathrm{p} 27^{\text {Kip }}$ than cyclin A-cdk2. We also characterized an H175 to R175 mutant of M-cyclin (denoted as H175R in Figure 1 and elsewhere in the text as M-cyclin) and showed that it has identical functional properties to wild-type M-cyclin (Figure 1B). Since this mutant had an improved solubility profile (G.L.Card, N.Jones and N.Q.McDonald, unpublished data), we concentrated our structural analysis on the H175R M-cyclin bound to cdk2.

M-cyclin-cdk2 complexes were prepared using an Escherichia coli host to produce M-cyclin and a recombinant baculovirus to produce cdk2 in Sf9 insect cells. The two purified proteins were mixed in solution and gel filtered prior to concentration and crystallization. In vitro kinase assays using histone $\mathrm{H} 1$ as substrate indicated that the M-cyclin-cdk2 complex was partially active in the absence of cdk2 phosphorylation at $\mathrm{T} 160^{\mathrm{k} 2}$ (Thr160 of cdk2, the superscript letter identifies the protein to which the residue belongs, i.e. A for cyclin A, $\mathrm{M}$ for M-cyclin, p27 for p27 Kip and k2 for cdk2) (data not shown). The same is also true for cyclin A-cdk2 (Russo et al., 1996b). We observed an $~ 50$-fold increase in kinase activity using $\mathrm{T} 160^{\mathrm{k} 2}$-phosphorylated cdk2 and M-cyclin (data not shown). Crystallization screens identified conditions that gave monoclinic crystals belonging to space group $\mathrm{P} 2{ }_{1}$ with cell dimensions $87.6 \times 73.5 \times 107.7 \AA$, $\beta=102.2^{\circ}$ and two M-cyclin-cdk2 complexes per
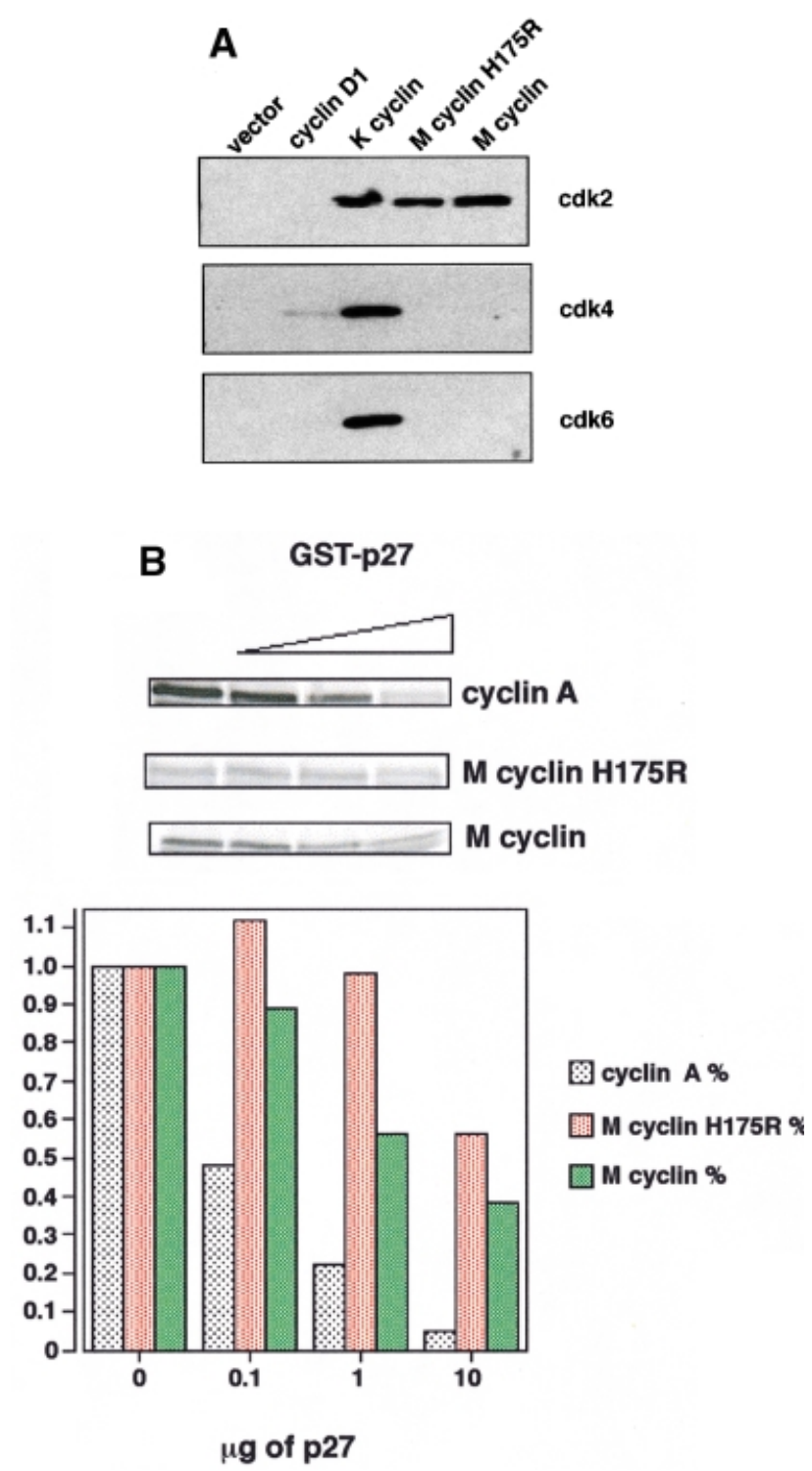

Fig. 1. (A) Wild-type and H175R M-cyclin associate with cdk2 but not with cdk4 or cdk6 in vivo, whilst K-cyclin associates with cdk2, cdk4 and cdk6. (B) The left panel shows wild-type and H175R M-cyclin complexes with cdk2 immunoprecipitated through the cyclin component and assayed against $\mathrm{pRb}$. In vitro kinase assays were performed in the presence of increasing amounts of p27 Kip and show the reduced sensitivity of wild-type and mutant M-cyclin towards this inhibitor compared with cyclin A. The lower panel shows a bar graph of the decrease in kinase activity due to increased inhibitor concentrations. ${ }^{32} \mathrm{P}$ counts incorporated into $\mathrm{pRb}$ were quantitated on a phosphoimager and normalized to the amount of total kinase activity present when no inhibitor was used.

asymmetric unit. These crystals grew as thin plates with dimensions rarely greater than $5 \mu \mathrm{m}$ and required intense synchrotron radiation to collect high resolution data from a single crystal. The M-cyclin-cdk2 structure was determined by molecular replacement and refined at $2.5 \AA$ to an $R$-factor of $23.5 \% \quad\left(R_{\text {free }}\right.$ of $\left.28.5 \%\right)$ with excellent geometry (Table I). There were no appreciable differences between the structures of either complex, and the rootmean-square deviation (r.m.s.d.) was $0.719 \AA$ for $529 \mathrm{C}_{\alpha}$ atoms. One of the two complexes (complex A) within the asymmetric unit had better defined electron density and correspondingly lower temperature factors, and only this 
Table I. Data processing and refinement statistics

\begin{tabular}{ll}
\hline X-ray source & ESRF, \\
& ID13 Microfocus beamline \\
Space group & $\mathrm{P} 21$ \\
Unit cell & $87.6 \times 73.5 \times 107.7 \AA$ \\
& $\beta=102.2^{\circ}$ \\
Resolution & $30-2.5 \AA$ \\
Total observations & 140317 \\
Unique reflections & 45057 \\
Intensity $I / \sigma I^{\mathrm{a}}$ & $5.7(1.6)$ \\
Completeness $^{\mathrm{a}}$ & $97.1 \%(95.6 \%)$ \\
$R_{\text {sym }}{ }^{\mathrm{a}}$ & $10.0 \%(37.9 \%)$ \\
$R_{\text {free }}(\%)$ & 28.5 \\
$R$-factor $(\%)$ & 23.5 \\
Non-hydrogen protein atoms & 8505 \\
Solvent molecules & 202 \\
Mean $B$-factor & \\
$\quad$ protein atoms $\left(\AA^{2}\right)$ & 37.46 \\
$\quad$ solvent molecules $\left(\AA^{2}\right)$ & 32.71 \\
R.m.s.d. from ideal stereochemistry & \\
$\quad$ bond lengths $(\AA)$ & 0.0088 \\
bond angles $\left({ }^{\circ}\right)$ & 1.41 \\
\hline
\end{tabular}

$R_{\mathrm{sym}}$ is defined as $\Sigma I-\langle I>| / \Sigma I$, where $I$ is the observed intensity and $\langle I\rangle$ is the average intensity from multiple measurements. $R$-factor is defined as $\Sigma F \mathrm{p}-|F \mathrm{c}| / \Sigma F \mathrm{p}$, where $\mid F \mathrm{pl}$ is the protein structure factor amplitude and $\mid F \mathrm{cl}$ is the calculated structure factor amplitude.

${ }^{a}$ Highest resolution shell in parentheses.

complex is discussed. For complex A, residues 6-252 of $\mathrm{M}$-cyclin are ordered, as are all of the residues in cdk2 with the exception of 10 and 11 .

\section{Overall structure of the M-cyclin-cdk2 complex}

The bi-lobal structure of cdk 2 comprises an ATP-binding site and catalytic centre located between an N-terminal (N-lobe) and C-terminal lobe (C-lobe). M-cyclin binds cdk2 by interacting with hydrophobic sequences from the PSTAIRE region (residues $38-56$ ) and strands $\beta 4 / \beta 5$ of the N-lobe (Figure 2). It also makes important contacts with the T-loop in the C-lobe (Figure 2C). The cdk2binding site on M-cyclin includes sequences within the cyclin box (residues 44-145) and the N-terminus (Figure 2 ). There are several unique features to the M-cyclin-cdk2 structure; M-cyclin binds cdk2 with a relative disposition different from that of cyclin A such that structurally equivalent residues make different contacts with cdk2 with few interactions identical to the cyclin $\mathrm{A}-\mathrm{cdk} 2$ interface (Figure 2C; Table II). The flexibility of the cdk2 N-lobe allows for an optimized packing with M-cyclin and ensures that M-cyclin is still able to partially activate cdk 2 by promoting the realignment of the PSTAIRE helix similarly to cyclin A.

\section{Basis for the resistance of M-cyclin-cdk2 to the p27 Kip cdk inhibitor}

Structural studies with a p27 ${ }^{K i p}$-derived peptide complexed to cyclin A-cdk2 have confirmed that two distinct binding sites for $\mathrm{p} 27^{\text {Kip }}$ exist within the cyclin A-cdk2 complex (Russo et al., 1996c). One is located in the cyclin subunit and a second in the ATP-binding cleft of the cdk subunit. Additional contacts are made with the cdk2 N-lobe as p27 Kip bridges these two independent sites (Russo et al., 1996c). To establish why viral cyclins such as $\mathrm{M}$ - and $\mathrm{K}$-cyclin form active complexes that are resistant to the cdk inhibitor $\mathrm{p} 27^{\text {Kip }}$, we examined equivalent regions on cyclin $\mathrm{A}$ and $\mathrm{M}$-cyclin that define the p27 ${ }^{\text {Kip }}$-binding site. As we predicted previously, the acidic residues $\mathrm{E} 220^{\mathrm{A}}$ and $\mathrm{D} 283^{\mathrm{A}}$, which form salt bridges with $\mathrm{R} 30^{\mathrm{p} 27}$ and $\mathrm{K} 25^{\mathrm{p} 27}$, are replaced by uncharged side chains in M-cyclin, suggesting that electrostatic repulsion prevents $\mathrm{p} 27^{\text {Kip }}$ interaction (Swanton et al., 1999). In addition, the presence of basic or polar residues $\mathrm{S} 93^{\mathrm{M}}$ and $\mathrm{K} 135^{\mathrm{M}}$ in place of $\mathrm{L} 255^{\mathrm{A}}$ and $\mathrm{L} 297^{\mathrm{A}}$ replaces two critical buried interface residues within the p27-cyclin A complex and would also be expected to disrupt the interaction between p27 ${ }^{\text {Kip }}$ and viral cyclins.

Unexpectedly, we found that two structural elements of M-cyclin also impede p27 Kip interaction. The main chain position of the H4-H5 loop leads to a steric clash with the p27 ${ }^{\text {Kip }}$ peptide conformation observed bound to cyclin A (Figure 3C). Also, one of two helices found only in M-cyclin, helix HC (residues 247-250), lies close to the cyclin A-binding site for $\mathrm{p} 27^{\text {Kip }}$ (Figure $3 \mathrm{C}$ ). This positions residue $\mathrm{F} 248^{\mathrm{M}}$ within $2.1-2.2 \AA$ of $\mathrm{R} 30^{\mathrm{p} 27}$ and $\mathrm{L} 32^{\mathrm{p} 27}$ side chains. It is also possible that the different disposition of the viral cyclin to cdk2 compared with cyclin A may further preclude interaction between $\mathrm{p} 27^{\text {Kip }}$ and viral cyclin by disrupting a continuous complementary surface bridging across from the cyclin to cdk2 (Russo et al., 1996c).

\section{Structural comparison of a viral and non-viral cyclin bound to cdk2}

Superposition of the cdk2 subunit from the cyclin A-cdk2 structure onto M-cyclin-cdk2 indicates no gross changes in cdk2 conformation (excepting the T-loop) with an r.m.s.d. of $1.209 \AA$ for $234 \mathrm{C}_{\alpha}$ atoms of cdk2 (from a total of 284). As mentioned previously, the superposition reveals that the M-cyclin is translated by $\sim 4 \AA$ towards the cdk2 N-lobe, relative to cyclin A (Figure 3A). This brings the $\mathrm{M}$-cyclin $\mathrm{N}$-terminus into the cdk2 interface and ensures that sequences from M-cyclin make different contacts with cdk2 than equivalent residues in cyclin $\mathrm{A}$ (Figure 4B; Table II). The M-cyclin-cdk2 interface has a smaller total buried surface area than that found for cyclin A-cdk2 (2269 $\AA_{\circ}^{2}$ compared with $3002 \AA^{2}$ ). M-cyclin contributes $1146 \AA^{2}$ to the complex (cyclin A contributes $1679 \AA^{2}$ ), of which just under a third is due to the $\mathrm{N}$-terminus. This is smaller than cyclin A as fewer side chains from helix HN1 participate in the M-cyclin-cdk2 interface (Figure 3B).

The major hydrophobic contacts in the M-cyclin-cdk2 interface centre on the PSTAIRE helix and strands $\beta 4$ and $\beta 5$ of the cdk 2 N-lobe (Figure 4A and B). A critical residue in this region is $\mathrm{W} 142^{\mathrm{M}}$, which packs against $\mathrm{H} 71^{\mathrm{k} 2}, \mathrm{~V} 69^{\mathrm{k} 2}$ and $\mathrm{L} 76^{\mathrm{k} 2}$ within a hairpin turn between strands $\beta 4$ and $\beta 5$ at the tip of the cdk2 N-lobe (Figure 4B). This region has much lower atomic temperature factors than the equivalent region of cyclin A-bound cdk2. The $\mathrm{C}_{\alpha}$ atoms of the equivalent residues $\mathrm{W} 142^{\mathrm{M}}$ and $\mathrm{F} 304^{\mathrm{A}}$ are $\sim 3.5 \AA$ apart but, in contrast to $\mathrm{W} 142^{\mathrm{M}}$, the side chain of $\mathrm{F} 304^{\mathrm{A}}$ makes van der Waals contact with $\mathrm{I} 52^{\mathrm{k} 2}$ of the PSTAIRE helix (Figure 4B). M-cyclin residues $\mathrm{I} 101^{\mathrm{M}}, \mathrm{V} 105^{\mathrm{M}}, \mathrm{L} 137^{\mathrm{M}}$ and $\mathrm{A} 144^{\mathrm{M}}$ define a shallow hydrophobic cavity, which packs against residue $\mathrm{I} 49^{\mathrm{k} 2}$ of the PSTAIRE helix (Figure 4A and $\mathrm{B})$. An equivalent cavity in cyclin $\mathrm{A}$ is located closer to the C-lobe of cdk2 (Figure 4A). Residues I49 ${ }^{\mathrm{k} 2}$ and L54 ${ }^{\mathrm{k} 2}$ 

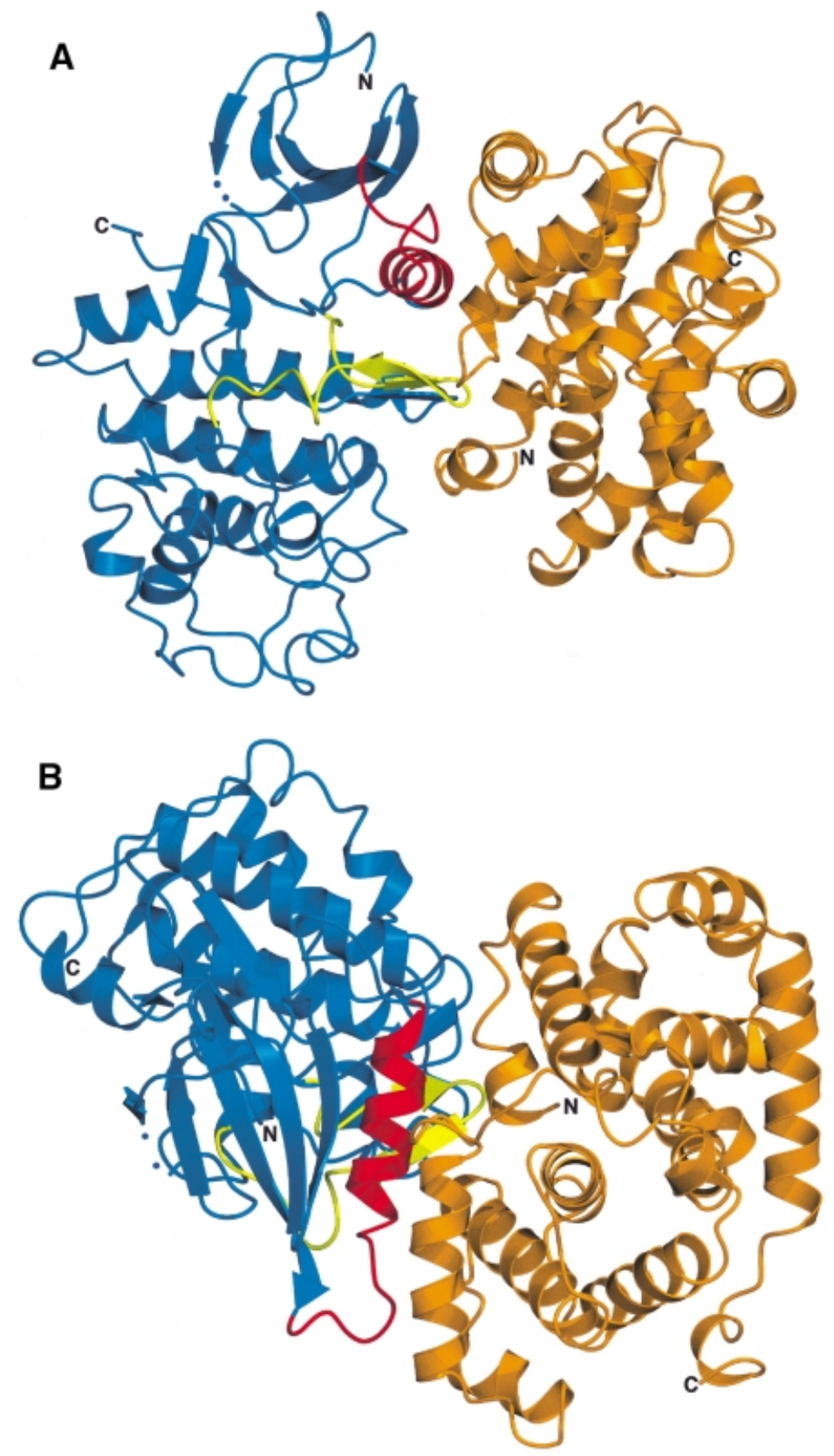

C

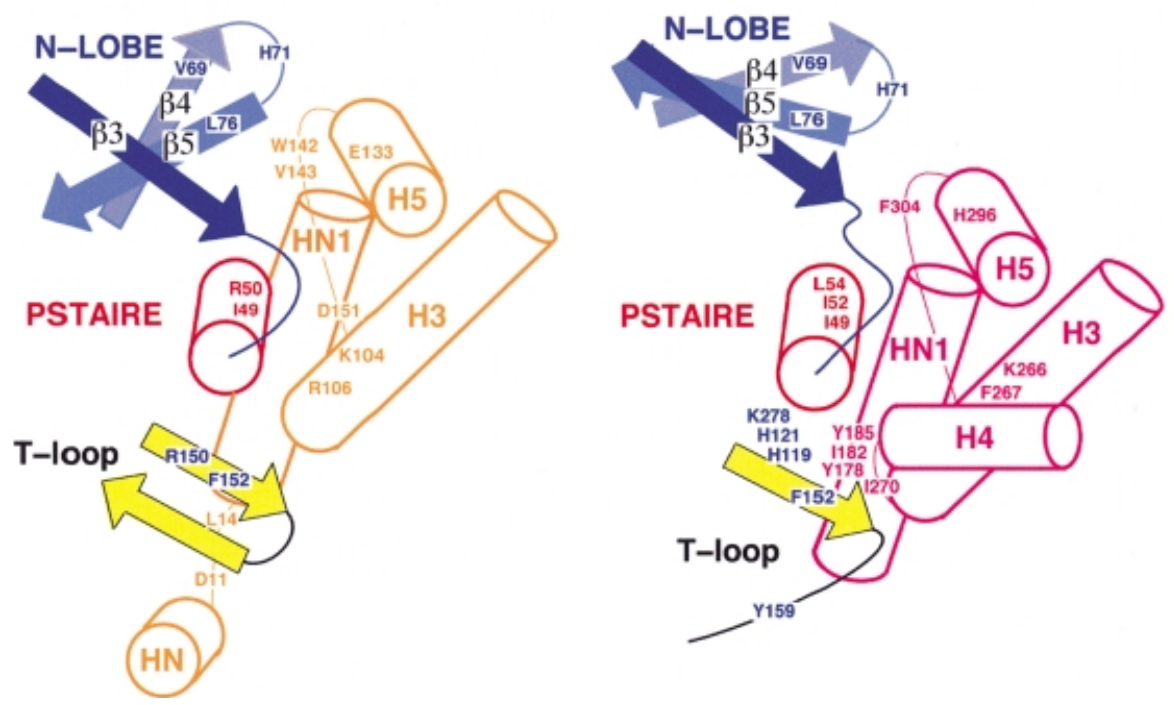


adopt different rotamers to cyclin A-bound cdk2, and the PSTAIRE helix is tilted at the N-terminal end optimizing packing interactions with M-cyclin (Figure 4A). In the M-cyclin-cdk2 structure, I49 ${ }^{\mathrm{k} 2}$ fills part of the space occupied by $\mathrm{F} 304^{\mathrm{A}}$ whilst $\mathrm{L} 54^{\mathrm{k} 2}$ tucks into the core of cdk2 towards the T-loop (Figure 4B). Also R50 ${ }^{\mathrm{k} 2}$ makes two hydrogen bonds to main chain carbonyl groups of K104 ${ }^{\mathrm{M}}$ and $\mathrm{A} 107^{\mathrm{M}}$, reminiscent of the hydrogen bonds it makes to cyclin A in phosphorylated cdk2 (Russo et al., 1996b).

Residues 6-16 of the M-cyclin tuck under F152 ${ }^{\mathrm{k} 2}$ of the T-loop, tethering this region at the centre of the cyclin-cdk interface. Notably, D1 $1^{\mathrm{M}}$ hydrogen-bonds with S181 ${ }^{\mathrm{k} 2}$ and forms a salt bridge to $\mathrm{R} 150^{\mathrm{k} 2}$ as discussed later. $\mathrm{L} 14^{\mathrm{M}}$ occupies a small pocket below R122 ${ }^{\mathrm{k} 2}$. These sequences form an important part of the cyclin-cdk interface and also contribute to a small hydrophobic core within M-cyclin, packing against several aromatic side chains from the cyclin box (F9 ${ }^{\mathrm{M}}$ and $\mathrm{L} 15^{\mathrm{M}}$ contact $\mathrm{C} 154^{\mathrm{M}}, \mathrm{Y} 155^{\mathrm{M}}, \mathrm{H} 158^{\mathrm{M}}$ and $\left.\mathrm{Y} 167^{\mathrm{M}}\right)$.

Of the few contacts to cdk2 conserved between both cyclin A and M-cyclin, the majority cluster either side of the PSTAIRE helix. The salt bridge formed by $\mathrm{K} 104^{\mathrm{M}}$ and $\mathrm{E} 133^{\mathrm{M}}$ (equivalent to $\mathrm{K} 266^{\mathrm{A}}$ and $\mathrm{E} 295^{\mathrm{A}}$ ) is of particular importance as it also makes three hydrogen bonds with cdk2, identical to cyclin A: one to the main chain carbonyl

\begin{tabular}{|c|c|c|c|}
\hline $\mathrm{Cdk} 2$ & M-cyclin & Cdk2 & Cyclin A \\
\hline & & t39 & K289 \\
\hline & & e40 & K288 \\
\hline \multirow[t]{2}{*}{ e42 } & K104 & e42 & K266 \\
\hline & & v44 & E295 \\
\hline \multirow[t]{2}{*}{ v44 } & K104 & v44 & K266 \\
\hline & & S46 & $\mathrm{k} 266$ \\
\hline R50 & k104 & R50 & $\mathrm{f} 267$ \\
\hline \multirow[t]{4}{*}{ R50 } & a107 & & \\
\hline & & S53 & d145 \\
\hline & & K56 & D305 \\
\hline & & E57 & Y185 \\
\hline H71 & D138 & H71 & H296 \\
\hline R122 & $\mathrm{d} 11$ & R122 & a307 \\
\hline R122 & Y155 & R122 & E269 \\
\hline \multirow[t]{4}{*}{ R150 } & D11 & R150 & e269 \\
\hline & & R150 & i270 \\
\hline & & v156 & N173 \\
\hline & & y180 & N173 \\
\hline \multicolumn{4}{|c|}{ S181 D11 } \\
\hline & & N272 & e174 \\
\hline & & S276 & D177 \\
\hline & & a277 & Y178 \\
\hline \multirow[t]{2}{*}{ K278 } & N16 & K278 & D181 \\
\hline & & $\mathrm{k} 278$ & Y178 \\
\hline
\end{tabular}

Hydrogen bonds were defined by CONTACT (CCP4, 1994). Side chain-side chain hydrogen bonds are indicated by upper case and side chain-main chain by lower case, with conserved bonds indicated in bold. A distance criterion of $3.2 \AA$ was used. The major hydrophobic contacts are shown in Figure 4B and are described in the text. group of $\mathrm{E} 42^{\mathrm{k} 2}$, and one to both the amide and carbonyl groups of $\mathrm{V} 44^{\mathrm{k} 2}$ (Table II). This is surprising in view of the different position of the two cyclins, but can be explained by a compensating shift in residues $42-51$ of $\mathrm{cdk} 2$, which include the N-terminal end of the PSTAIRE helix and its preceding loop (Figure 4C). The position of the PSTAIRE helix in the M-cyclin-cdk2 structure still permits E51 ${ }^{\mathrm{k} 2}$ to salt-bridge with the functionally important $\mathrm{K} 33^{\mathrm{k} 2}(2.7 \AA$ $\mathrm{O} \varepsilon 1$ of $\mathrm{E} 51^{\mathrm{A}}$ to $\mathrm{N} \zeta \mathrm{K} 33^{\mathrm{A}}$ ), analogous to the situation with cyclin A (Jeffrey et al., 1995). L130 ${ }^{\mathrm{M}}$ and $\mathrm{L} 137^{\mathrm{M}}$ (equivalent to L292 ${ }^{\mathrm{A}}$ and L299A) flank either side of the K104 ${ }^{\mathrm{M}}-\mathrm{E} 133^{\mathrm{M}}$ salt bridge, the latter being part of the cavity contacting the PSTAIRE helix described earlier. Close to the C-terminal end of the PSTAIRE helix, V143 ${ }^{\mathrm{k} 2}$ packs against the aliphatic portion of $\mathrm{K} 104^{\mathrm{M}}$, as well as side chains from $\mathrm{R} 26^{\mathrm{M}}$ and $\mathrm{D} 145^{\mathrm{M}}$, which form an ion pair and also make van der Waal contacts to $\mathrm{F} 152^{\mathrm{k} 2}$. Also, $\mathrm{D} 19^{\mathrm{M}}$ (equivalent to $\mathrm{D} 181^{\mathrm{A}}$ ) makes a favourable charge interaction with $\mathrm{K} 278^{\mathrm{k} 2}$ but is too distant to form the salt bridge seen for cyclin A-cdk2. Four ordered water molecules are also found at the cyclin-cdk interface, of which the most significant solvent-mediated contact is that between the $\mathrm{O} \varepsilon 1$ atom of $\mathrm{E} 133^{\mathrm{M}}$ and carbonyl oxygen of $\mathrm{V} 44^{\mathrm{k} 2}$, identical to that seen in cyclin A (Oع1 atom of E295 ${ }^{\mathrm{A}}$ ) (Figure 4C).

\section{T-loop conformation in the M-cyclin-cdk2 complex}

The conformation of the T-loop of cdk 2 is highly sensitive to phosphorylation of $\mathrm{T} 160^{\mathrm{k} 2}$ by cdk-activating protein kinases and to the presence of a bound cyclin subunit (Jeffrey et al., 1995; Russo et al., 1996b). Both M-cyclincdk2 complexes within the asymmetric unit have an identical T-loop conformation and this differs appreciably from previously reported structures. T-loop residues $148-$ 157 form two antiparallel $\beta$-strands as part of a threestranded $\beta$-sheet directly below the PSTAIRE helix (Figures 2 and 5B). This $\beta$-sheet platform contributes several hydrophobic side chains, which pack against the PSTAIRE helix, notably A149k2 $\mathrm{A} 151^{\mathrm{k} 2}$ and $\mathrm{V} 156^{\mathrm{k} 2}$. In contrast, other sequences in this region, including $\mathrm{R} 150^{\mathrm{k} 2}$, $\mathrm{F} 152^{\mathrm{k} 2}$ and $\mathrm{V} 154^{\mathrm{k} 2}$, are involved intimately in the M-cyclin-cdk2 interface (Figures $4 \mathrm{~B}$ and $5 \mathrm{~B}$ ). In particular, $\mathrm{R} 150^{\mathrm{k} 2}$ forms a salt bridge with $\mathrm{D} 11^{\mathrm{M}}$ from the $\mathrm{N}$-terminus of M-cyclin and adopts a quite different position to that found in cyclin A-activated cdk2 (Figure $5 \mathrm{~A}$ and $\mathrm{B}$ ). $\mathrm{R} 150^{\mathrm{k} 2}$ is one of three arginine side chains that coordinate phospho-T160k2 in cyclin A-bound cdk2 (Figure 5B) (Russo et al., 1996b). The other two arginines in close proximity, $\mathrm{R} 50^{\mathrm{k} 2}$ and $\mathrm{R} 126^{\mathrm{k} 2}$, have a very similar conformation to that seen in a cyclin A-phosphorylated cdk2 complex (Russo et al., 1996b).

The conformation of T-loop residues 157-165, including $\mathrm{T} 160^{\mathrm{k} 2}$, also deviates from that seen in previous structures. Comparison with a cyclin A-phosphorylated cdk2 bound to a substrate peptide indicates that the T-loop

Fig. 2. (A) Structure of the M-cyclin-cdk2 complex. Cdk2 is shown in blue except for the PSTAIRE region (residues 38-56) in red and the T-loop (residues 146-166) in yellow. M-cyclin is shown in gold. (B) An equivalent view following rotation by $90^{\circ}$ about the horizontal axis. The T-loop forms two antiparallel $\beta$-strands, which are sandwiched between the PSTAIRE helix and the N-terminal region of M-cyclin. This figure and Figure 3A were prepared using PREPI (S.Islam and M.J.Sternberg, unpublished). (C) Highly schematic view of the two cyclin-cdk interfaces illustrating key structural elements and selected interface residues. The left hand panel is M-cyclin-cdk2, the right hand panel is cyclin A-cdk2. Colours for the indicated secondary structures follow (A) and Figure 3A. 
lies directly along the path of a substrate peptide with several steric clashes and may contribute to the partial activity exhibited by the M-cyclin-cdk2 complex.
Similarly to the T-loop of cyclin A-bound unphosphorylated cdk2, V164 ${ }^{\mathrm{k} 2}$ does not adopt an $\alpha_{\mathrm{L}}$ conformation critical for substrate binding (Brown et al., 1999).
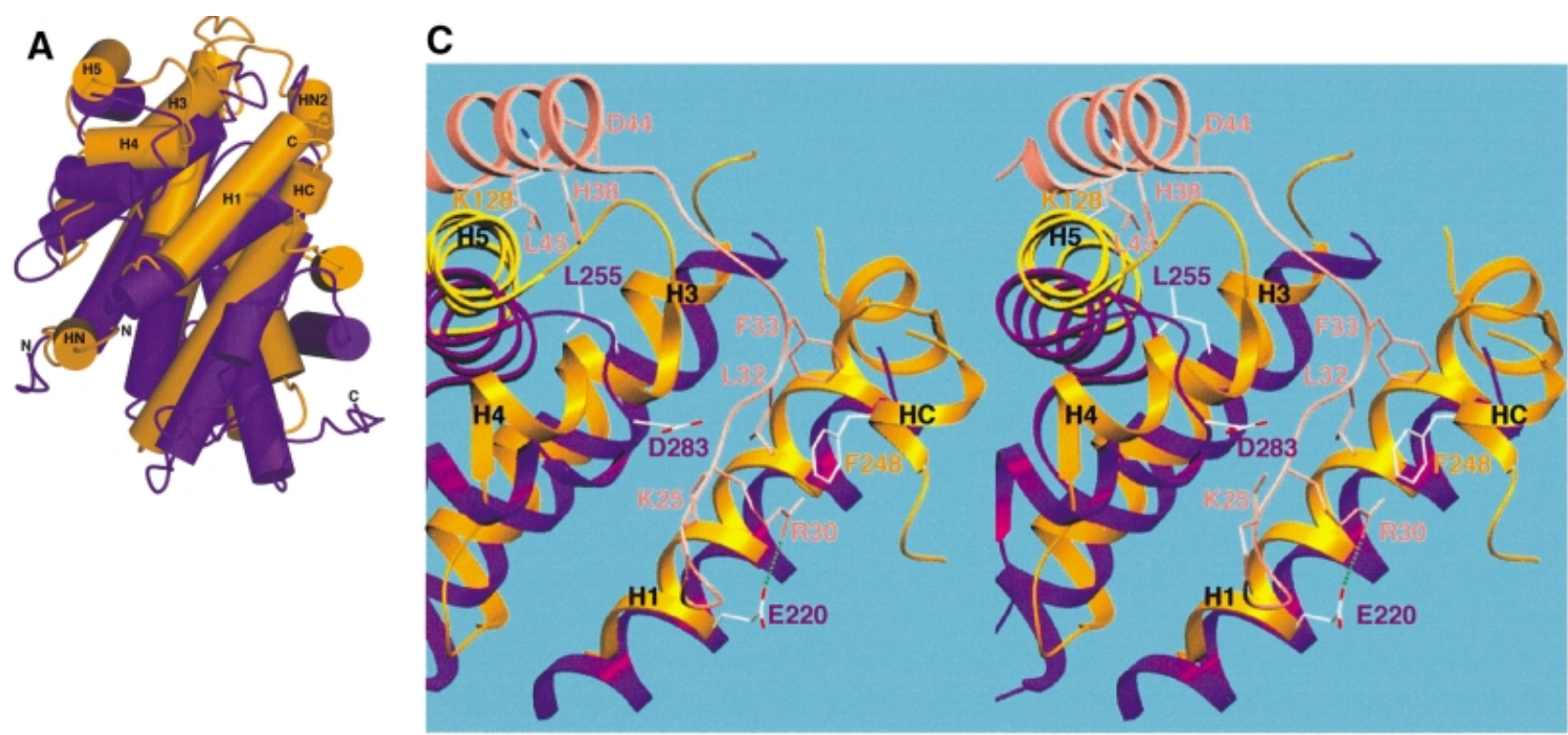

B
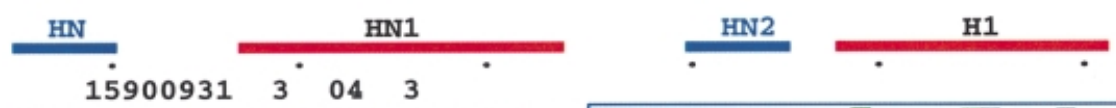

MASQEFQGFLDSSLLNEEDCRQMIYRSEREHDARMVGVN . VDQHFTSQYRKVLTTWIFCVCKDLRQDNN MATANNPPSGLIDPTLC. EDRIFYNILEIEPRFLTSDSVFGSFQQSLTSHMRKLLGTWMF SVCQEYNLEPN MADSPNRLNRAKIDSTTM . KDPRVLNNLKLRELLLPKFTSLWEIQTEVTVDNRTILLTKMHLLCESFELDKS MEHOLLCCE . VETIRRAYPDANLL . NDRVLRAMLKAEETCAPSV SYFKCVQKEVLPSMIKIVATWULEVCEEQKCEEE MELLCHE. VDPVRRAVRDRNLLRDDRVLQNLLTIEERYLPQCSYFKCVQKDIQPYMURMVATWMLEVCEEQKCEEE MELLCCEGTRHAPRA GPDPRLLGDQRVLQSLLRLEERYVPRA SYFQCVQREIKPHMIKMILAYWMLEVCEEQRCEEE 155 PHTMDMSIVLEDEKPVSVNEVPDYHEDIHTYLREMEVKCKPKVGYMK . KQPDITNSMDAILVDWLVEVGEEYKLQNE 92804900380091001

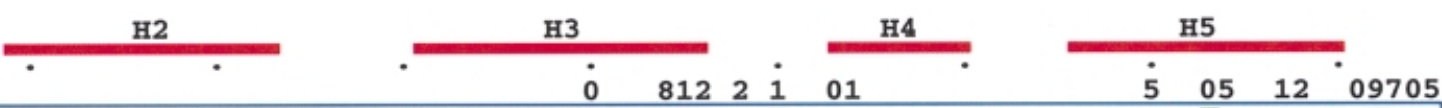

VFPRAVALIDELFLSTRIDRENYOSTAAVALHIAGEV AYMPIKATOIAYLCGGATTADKILTL FVKSLDTLSWVAD VVAIALNLLPRLLLIKQVSKEHF CKTGSACLLVASTL SLTPISTSSICYAAADSFSRQELIDQ IKELLEKLAWRTE VFPISVSIIDRYLCKKQGTKKTLOKIGAACVLIGSTITVKPMTVSKITYLSCDCFTNLEL INQ TKDILEALKWTE VFP IAMNYLDRFLSLEPVKKSRL LLGATCMFVASIKM ETIPLTAEKLCIYTDGSIRPEELLQMILLLVNKLKWNLA VFP IAMNYLDFLAGVPTPKSHL LLGAVCMFLASIL ET SPLTAEKLCIYTDNSIKPQELLEWILVVLGKL KWNLA VFP DAMNYLDRLSCVPTRKAQL OLLGAVCMLLASTLETTPLTIEKLCIYTDHAVSPRQLRDW VLVLGKL KWDLA

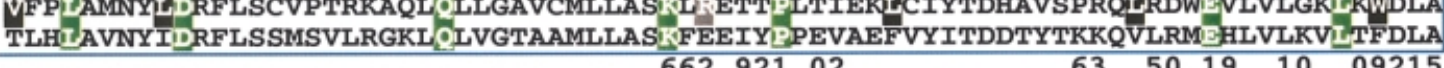
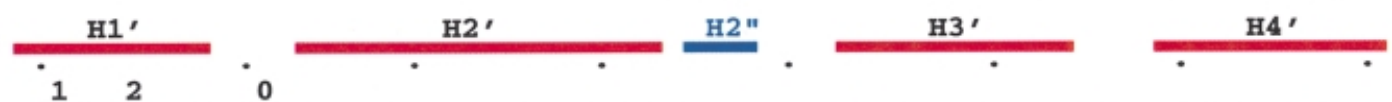

$\begin{array}{lr}\text { LYITKEELHQCCDLVDIAIVSFDENYFKINA* } & 252 \\ \text { LASILGCDVSVLQAAVEQILTSVSDFDLRILDSY* } & 257\end{array}$

SSI. LNF STNTVRTVKDQVSEAFSLYDLEIL*

RFLSRVIKCDPDCLRACQEQIEALLESSLRQAQQNMDPKAAEEEEEEEEE . VDLACTPTDVRDVDI* ELLAKITNTDVDCLKACQEQIEAVLLNSLQQYRQDQ . . . . . RDGSKSEDE. LDQASTPTDVRDIDL* ELLAGITGTEVDCLRACQEQIEAALRESLREASQTSSSPAPKAPRGSSSQGPSQTSTPTDVTAIHL * .GYTLESLKPCLMDLHQTYLKAPQHAQQSIREKYKNSKYHGVSLLNPPETLNL * 


\section{M-cyclin-cdk2 as a model for other cyclin-cdk complexes}

In order to establish whether the M-cyclin-cdk2 complex would provide a good model for other viral and D-type cyclin-cdk complexes, we first compared the structure of M-cyclin with those of V-cyclin and cyclin A (Brown et al., 1995; Jeffrey et al., 1995; Schulze-Gahmen et al., 1999). The r.m.s.d. is $1.44 \AA$ for $164 \mathrm{C}_{\alpha}$ atoms between M-cyclin and cyclin $\mathrm{A}$, and $1.79 \AA$ for $173 \mathrm{C}_{\alpha}$ atoms between M-cyclin and V-cyclin. Superposition of the three cyclins reveals several structural elements unique to M-cyclin. These include helices HN and HN2, the H4H5 loop and helix HC (Figure 3B). Helices HN and HC were not observed in the V-cyclin structure due either to flexibility or to the intermediate resolution of the structure (Schulze-Gahmen et al., 1999), whereas sequences in V-cyclin and cyclin A equivalent to helix HN2 adopt a loop conformation. The H4-H5 loop is more extended in M-cyclin than in other cyclins and has the sequence $\mathrm{G} 121^{\mathrm{M}}, \mathrm{G} 122^{\mathrm{M}}$ and $\mathrm{A} 123^{\mathrm{M}}$, which overlaps the $\mathrm{p} 27^{\mathrm{Kip}_{-}}$ binding site on cyclin $\mathrm{A}$, as described earlier.

The majority of sequences conserved between the M-cyclin and V-cyclin are located within their buried cores, and these proteins clearly demonstrate a closer structural relationship with one another than with cyclin A (Figure 3B). This is consistent with the sequence similarity of viral cyclins and cellular cyclins in the cyclin box (the second helical cyclin domain is far more divergent in sequence than the cyclin box and is therefore an unreliable guide). The cyclin box of M-cyclin shares $36 \%$ identity to $\mathrm{K}$-cyclin and $30 \%$ to V-cyclin and cyclin D3, compared with $23 \%$ identity to cyclin A. Several residues on the surface of M-cyclin and V-cyclin are also strictly conserved in all viral cyclin and D-type cyclin sequences (Figure 3B). These include D11 $, \mathrm{W} 142^{\mathrm{M}}, \mathrm{D} 151^{\mathrm{M}}$ and $\mathrm{R} 106^{\mathrm{M}}$ (conserved as a basic side chain; $\mathrm{R} 106^{\mathrm{M}}$ forms a salt bridge with $\mathrm{D} 151^{\mathrm{M}}$ ), all of which contribute to the M-cyclin-cdk2 interface. This 'fingerprint' is distinct from the nine residues that are conserved amongst the majority of mammalian cyclin sequences, six of which are buried within the cyclin hydrophobic core $\left(\mathrm{R} 49^{\mathrm{M}}, \mathrm{W} 55^{\mathrm{M}}, \mathrm{L} 72^{\mathrm{M}}\right.$, $\mathrm{D} 78^{\mathrm{M}}, \mathrm{Q}^{\mathrm{M}}$ and $\mathrm{L} 140^{\mathrm{M}}$ ) whereas the other three contribute to the cdk interface $\left(\mathrm{K} 104^{\mathrm{M}}, \mathrm{P} 110^{\mathrm{M}}\right.$ and $\left.\mathrm{E} 133^{\mathrm{M}}\right)$. We therefore propose that the presence of the four conserved surface residues in viral and D-type cyclins is consistent with these cyclins engaging their cdk partners in a manner similar to M-cyclin.

\section{Discussion}

To understand the basis of viral cyclin interaction with mammalian cdk enzymes, we have focused our biochemical and structural efforts on M-cyclin, the viral cyclin from murine $\gamma$-herpesvirus 68 (Virgin et al., 1997). Although the in vivo oncogenic effects of M-cyclin expression have been established in transgenic mice (van Dyk et al., 1999), its molecular properties remain uncharacterized. We first examined M-cyclin's ability to associate with and activate different cdks and showed that its preferred cdk partner is cdk2, similar to cyclins A and E. M-cyclin differs from other viral cyclins in its restricted cdk preference. For example, K-cyclin is more promiscuous and can activate cdk2, cdk4 and cdk6 (Godden-Kent et al., 1997; Mann et al., 1999). We also demonstrated that M-cyclin is able to reduce the sensitivity of cdk2 to inhibition by $\mathrm{p} 27^{\text {Kip }}$ by at least 10 -fold, analogous to the ability of K-cyclin to block inhibition of cdk6 by p27 Kip (Swanton et al., 1997).

We then determined the crystal structure of a partially active M-cyclin-cdk2 complex at $2.5 \AA$ resolution by molecular replacement. This structure provides the first crystallographic evidence that significant differences exist in the way two different cyclins can bind to and activate the same cdk subunit. This has important implications for other cyclin-cdk complexes. M-cyclin and cyclin A bind to cdk2 and activate it through repositioning the same cdk structural elements. Remarkably, however, the different relative disposition of cyclin and cdk in each complex ensures that very few interface contacts are conserved identically. The exception is the $\mathrm{K} 104^{\mathrm{M}} / \mathrm{E} 133^{\mathrm{M}}$ sequence which contacts carbonyl and amide groups of $\mathrm{E} 42^{\mathrm{k} 2}$ and $\mathrm{V} 44^{\mathrm{k} 2}$, a 'hot spot' binding epitope at the cyclin-cdk interface. That such differences might exist was suggested from a model for $\mathrm{V}$-cyclin-cdk6 derived from cyclin Acdk2, which indicated several bad contacts close to the PSTAIRE helix and elsewhere (Schulze-Gahmen et al., 1999).

The different cyclin disposition in M-cyclin-cdk2 is indicative of the plasticity of the cyclin-cdk interface. Despite a translation of $4 \AA$ relative to cyclin $A$, M-cyclin packs against the cdk2 N-lobe using primarily hydrophobic interactions close to $\mathrm{W} 142^{\mathrm{M}}$ and the PSTAIRE helix. The conformational flexibility of cdk2 within the N-lobe allows for optimization of interactions with $\mathrm{M}$-cyclin close to $\mathrm{W} 142^{\mathrm{M}}$ by readjusting the position of the hairpin turn between strands $\beta 4$ and $\beta 5$. Although

Fig. 3. (A) Relative position of M-cyclin (gold) and cyclin A (purple) following superposition through their respective cdk2 subunits. The helices of each cyclin are rendered as cylinders emphasizing the structural differences close to the M-cyclin N- and C-termini. These regions have important implications for interaction with the cdk2 T-loop and the basis for p2 $7^{\text {Kip }}$ resistance as described in the text. Helices of M-cyclin referred to in the text are labelled. (B) Sequence alignment of three viral cyclins (accession codes: mhu91858, cgh2 hsvsa and ksu79416) with the D-type cyclins (accession codes: hscycd1, hscycd2 and hscycd3) and cyclin A3 (accession code: hscyclina). M-cyclin, V-cyclin and cyclin A3 were aligned based on structural superposition and analysis using SAP (Taylor and Orengo, 1989). Helices in M-cyclin are indicated by boxes above the sequences and named following the convention used by Schulze-Gahmen et al. (1999). The blue outline box highlights the cyclin box. The helices unique to M-cyclin are shown as blue boxes. Every tenth residue in the M-cyclin is marked with a dot. Conserved residues amongst mammalian cyclins are highlighted in green, whereas those specific to the viral and D-type cyclins are shaded black in reverse contrast or grey for R106 ${ }^{\mathrm{M}}$ (see text). M-cyclin (above sequences) and cyclin A (below sequences) residues contributing to the cdk interface are indicated by a number representing the amount of surface area of the side chain buried in the cyclin-cdk 2 interface. 0 represents $1-10 \AA^{2}$, up to 9 , which indicates that $>91 \AA^{2}$ of the side chain is buried in the interface. (C) Stereo view of the p27 Kip-binding site of cyclin A (purple) and the equivalent region of M-cyclin (gold) following superposition through their respective cdk2 subunits. p $27^{\text {Kip }}$ is shown in pink. Some residues are omitted from the figure for clarity. 
the PSTAIRE helix orientation differs slightly from that found in cyclin $\mathrm{A}-\mathrm{cdk} 2$, it still suffices to preserve the interaction of $\mathrm{E} 51^{\mathrm{k} 2}$ with $\mathrm{K} 33^{\mathrm{k} 2}$ required for $\mathrm{cdk} 2$ catalytic activation. A further consequence of the position of M-cyclin bound to cdk2 is that almost half of the cdk2 T-loop is buried within the interface pincered between the $\mathrm{N}$-terminus of $\mathrm{M}$-cyclin and the PSTAIRE helix (Figure 2C). The presence of the $\mathrm{N}$-terminus of M-cyclin within the interface with cdk2 was unexpected, but in preliminary experiments we have confirmed that deletion mutants of M-cyclin lacking these sequences are unable to bind or activate cdk2 in vitro (P.Knowles and N.Q.McDonald, unpublished). Equivalent $\mathrm{N}$-terminal sequences were not observed in the V-cyclin structure, which was determined in the absence of a bound cdk subunit (Schulze-Gahmen et al., 1999). This suggests that binding to the cdk subunit increases the degree of order in these sequences.

One of the remarkable features of viral cyclins is their capacity to evade inhibition by CKIs, suggesting that their expression would result in unrestrained cdk kinase activity in an infected cell. Previous predictions anticipated that sequence differences near the p27 ${ }^{K i p}$-binding site on viral cyclins would render it non-functional (Swanton et al., 1999). From our M-cyclin-cdk2 structure, a more complex molecular explanation emerges for the inability of p27 Kip to inhibit active viral cyclin-cdk complexes. Rather than single or multiple sequence changes in the cyclin, it is a combination of sequence and conformational variation, particularly the main chain position of two structural
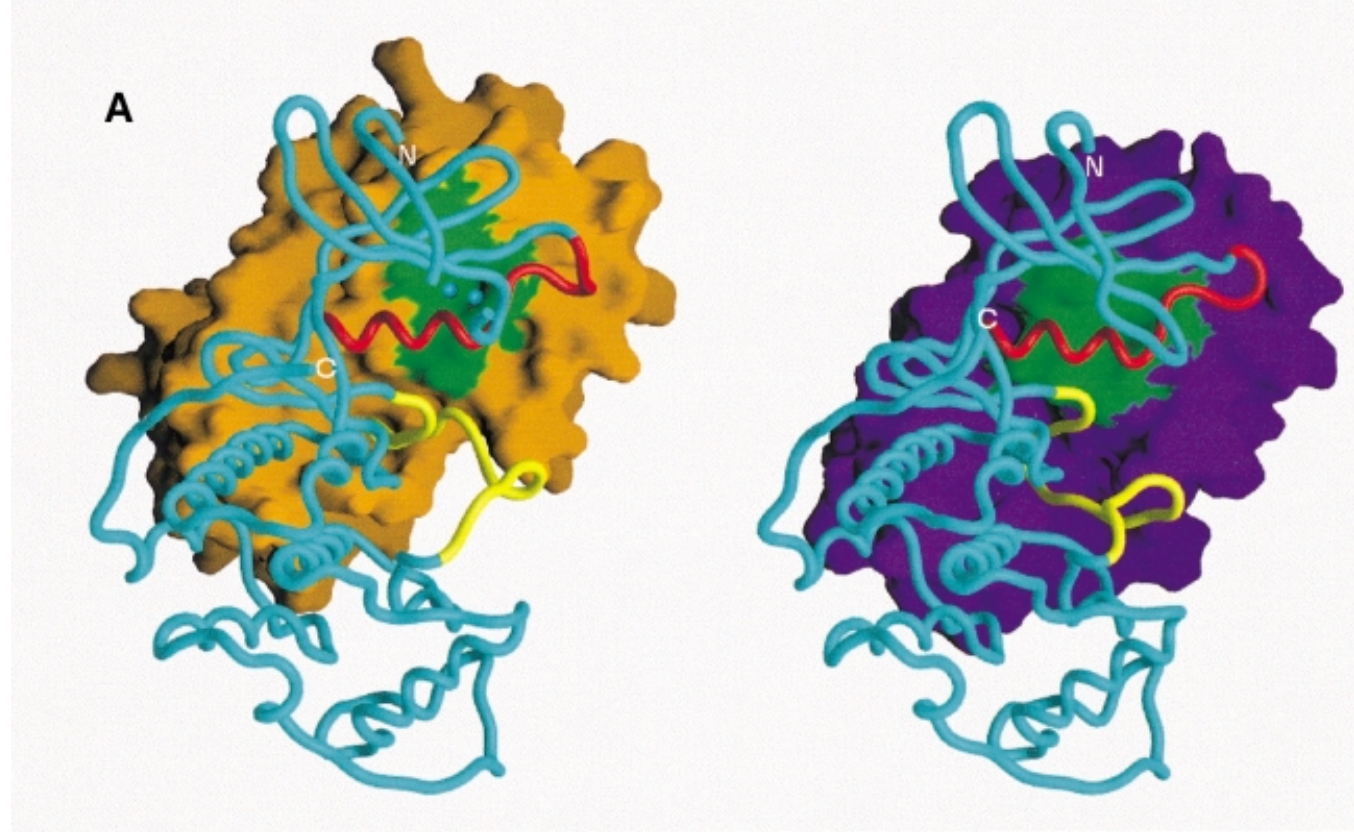

B
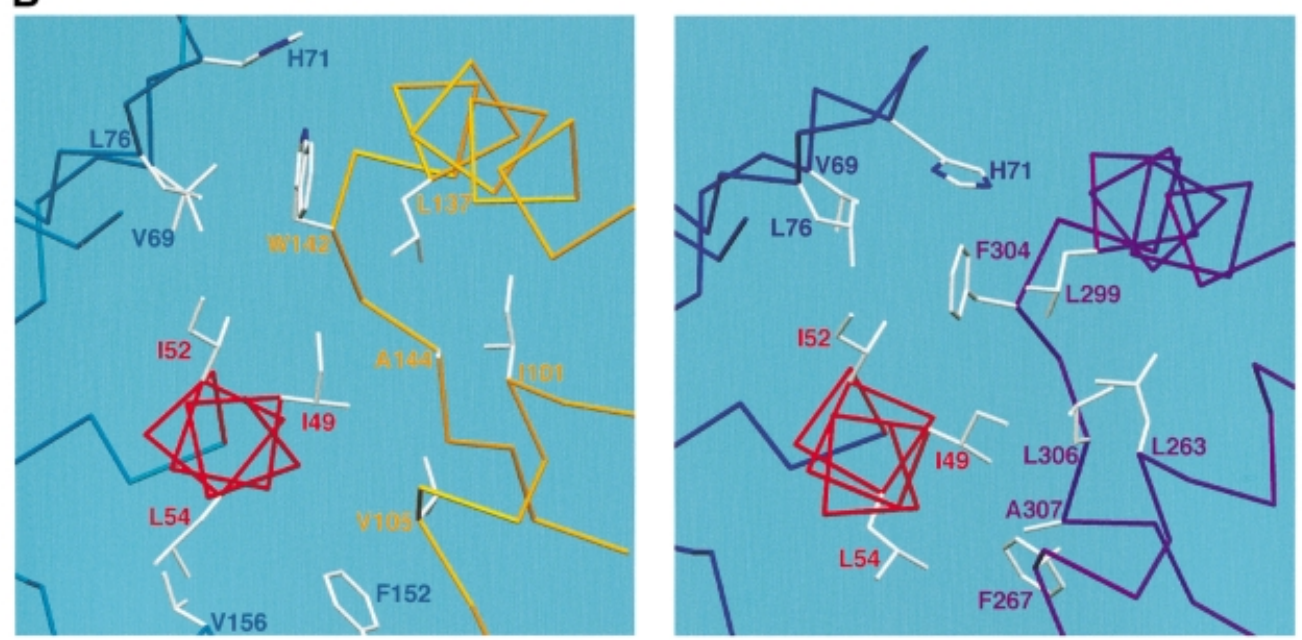

Fig. 4. (A) Surface representation of M-cyclin (gold, left) and cyclin A (purple, right) bound to their respective cdk2 partners (cyan $\mathrm{C}_{\alpha}$ worm). The cdk2 PSTAIRE region is shown in red and the T-loop in yellow for both complexes as in Figure 2. The green surface of M-cyclin and cyclin A indicates the hydrophobic patch, which packs against the PSTAIRE helix. The shift in position of M-cyclin relative to cyclin A can be seen as well as the different contacts to the PSTAIRE helix. (B) Close-up of the hydrophobic patch of M-cyclin-cdk2 and cyclin A-cdk2 revealing differences in their interface contacts. (C) Stereo view of a conserved cyclin-cdk2 interaction centred on the salt bridge between K104 ${ }^{\mathrm{M}}$ and E133 ${ }^{\mathrm{M}}$ (top view) equivalent to $\mathrm{K}_{266^{\mathrm{A}}}$ and $\mathrm{E} 295^{\mathrm{A}}$ (bottom view) as described in the text. Certain residues in this region are omitted for clarity. 
elements (the H4-H5 loop and helix HC), that leads to a markedly reduced affinity for $\mathrm{p} 27^{\mathrm{Kip}}$. In order to bind M-cyclin-cdk2, p27 Kip would have to overcome both unfavourable electrostatic and steric interactions. Several reports indicate that cyclin D-cdk6 complexes are able to engage $\mathrm{p} 27^{\text {Kip }}$ but are not inhibited by $\mathrm{p} 27^{\text {Kip }}$ in vivo (reviewed in Sherr and Roberts, 1999). Whether the different mode of cdk engagement we describe for M-cyclin is used by cyclin D and how this perturbs p2 $7^{K i p}$-cdk6 interaction and cdk6 activity are important questions raised by our study.

The T-loop conformation observed in M-cyclin-cdk2 differs considerably from that seen in other cdk2 structures (Jeffrey et al., 1995; Russo et al., 1996b; Brown et al., 1999). For example, F152 $2^{\mathrm{k} 2}$ of the T-loop is buried within the complex interface and the viral cyclin $\mathrm{D} 11^{\mathrm{M}}$ chelates $\mathrm{R} 150^{\mathrm{k} 2}$, tethering this portion of the T-loop. We anticipate that it is unlikely that residues 146-157 change conformation upon $\mathrm{T} 160^{\mathrm{k} 2}$ phosphorylation. However, residues 158-166 could reorganize about phosphorylated $\mathrm{T} 160^{\mathrm{k} 2}$ as in cyclin A-bound cdk2 such that $\mathrm{V} 164^{\mathrm{k} 2}$ adopts an $\alpha_{\mathrm{L}}$ conformation to form the $\mathrm{P}+1$ pocket specific for the proline residue in cdk target sites (Russo et al., 1996b; Brown et al., 1999). Since the viral cyclin-cdk complex is partially active, we infer that the C-terminal part of the T-loop must exhibit some flexibility in solution.

Viral cyclins are known to alter the substrate specificity of their cdk partners (Godden-Kent et al., 1997; Ellis et al., 1999; Mann et al., 1999) and are able to elicit a higher level of kinase activity than D-type cyclin-cdk6 complexes. Both of these properties may reflect the conformation of the phosphorylated T-loop bound to viral cyclin, and this will be clarified by structures of ternary complexes of substrate-viral cyclin-cdk. We cannot at present address whether the viral cyclin influences substrate selection directly through the close proximity of its N-terminus to the T-loop or indirectly by altering the T-loop conformation to promote interaction with appropriate substrates. We note that sequences within the D-type cyclin $\mathrm{N}$-terminus have previously been implicated in recruitment of cdk substrates such as pRb
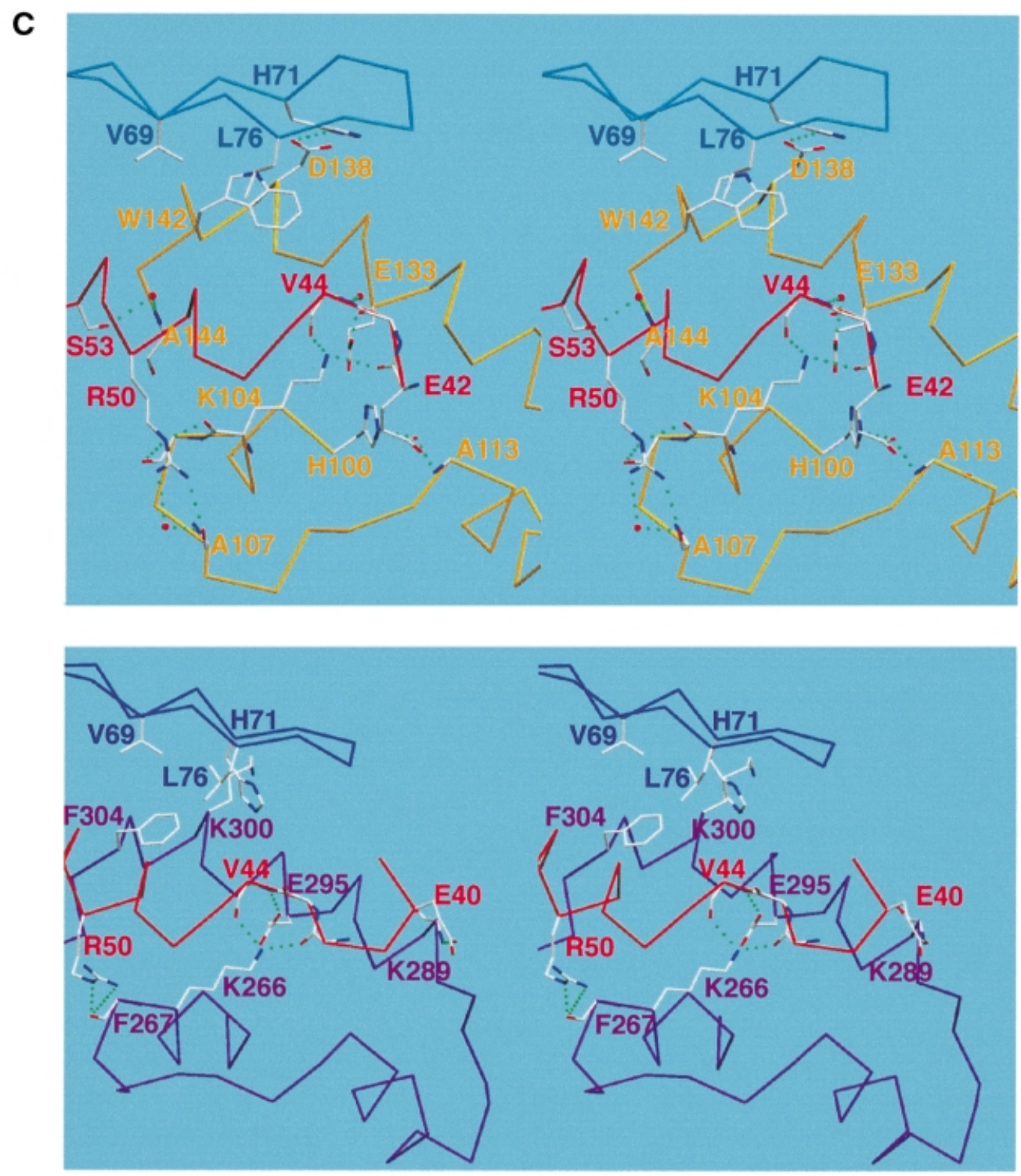


\section{G.L.Card et al.}

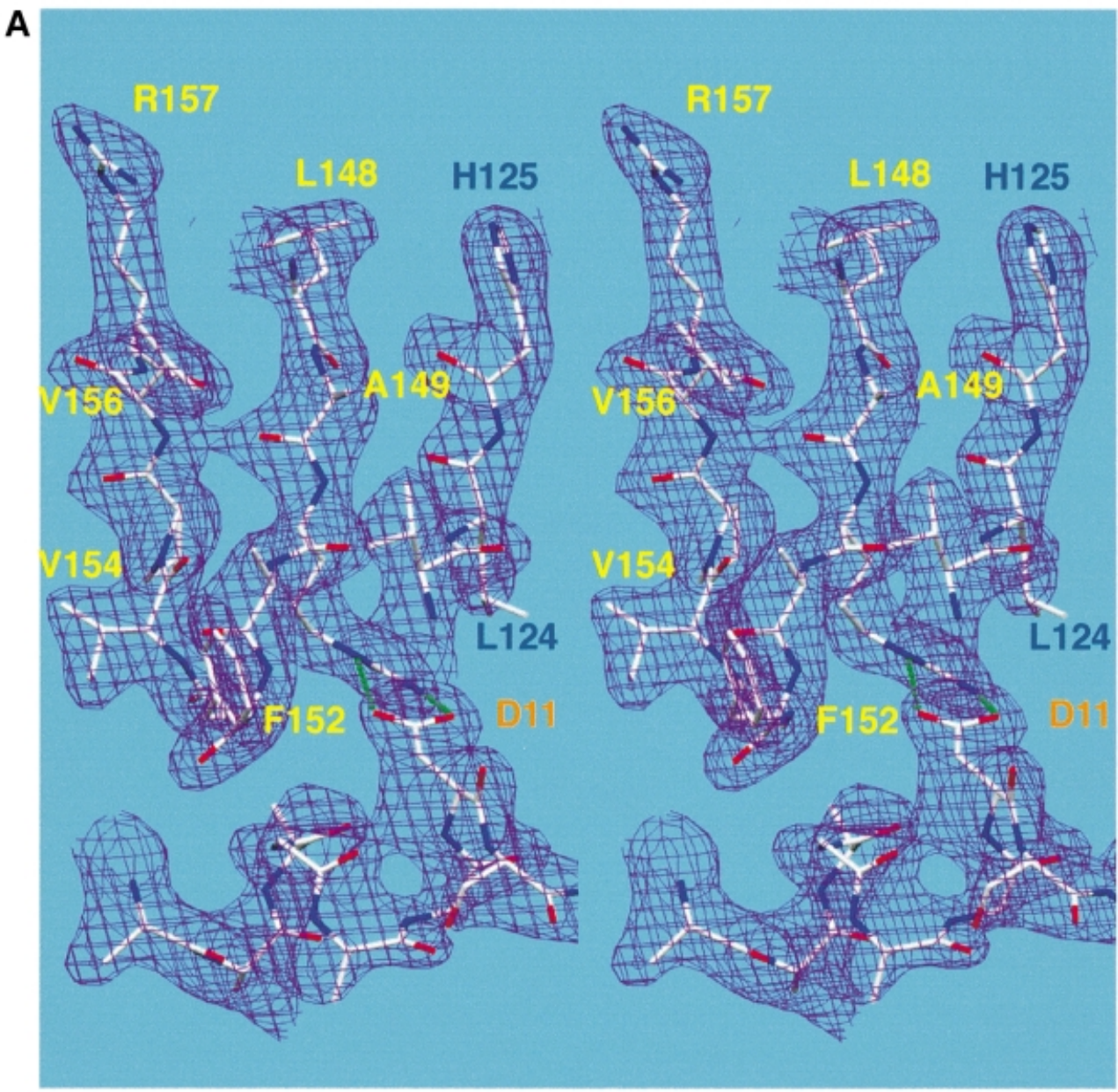

B
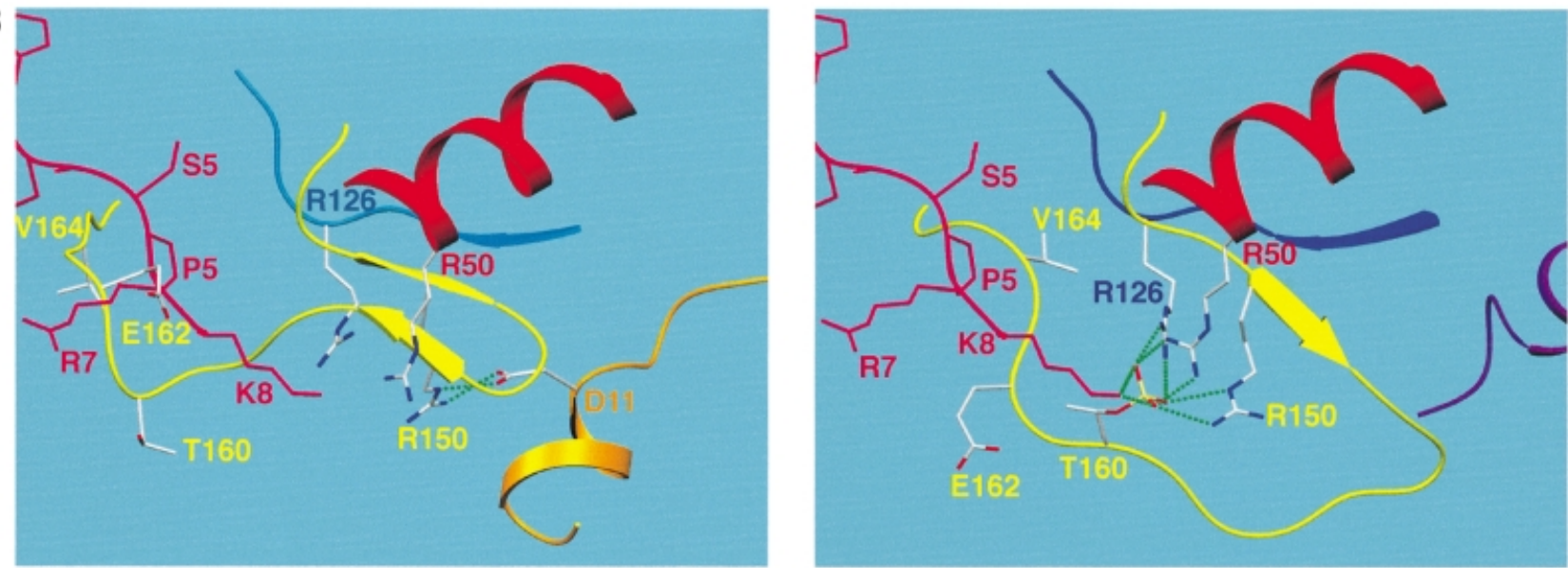

Fig. 5. (A) Stereo view of the electron density at the interface of the cdk2 T-loop and the N-terminus of M-cyclin in the last stage of refinement. The $\left(2\left|F_{\mathrm{o}}\right|-\left|F_{\mathrm{c}}\right|\right)$ Fourier synthesis was calculated at $2.5 \AA$ and the map contoured at $1.2 \sigma$. T-loop residues are labelled in yellow, and M-cyclin N-terminal residues in gold. (B) Close-up view of the T-loop of cdk2 (yellow) in complex with M-cyclin (top) or cyclin A (bottom). Coordinates of a substrate peptide are also shown derived from the cyclin A-phosphorylated cdk2 complex (Brown et al., 1999). Superposition of the substrate peptide onto M-cyclin-cdk2 shows a number of steric clashes in the region of the T-loop.

via the LXCXE motif, which is absent from the viral cyclins (Kato et al., 1993).

Whether the M-cyclin-cdk2 complex reveals a novel virus-specific configuration or one that is more widely shared by other cyclins must await further viral cyclin-cdk crystal structures. Given the highly divergent nature of the cyclin sequences, we note that there would need to be considerable selective pressure to retain a particular residue because it plays either a key structural role or a functional role such as contributing to cdk binding. The conservation of sequences $\mathrm{D} 11^{\mathrm{M}}, \mathrm{R} 106^{\mathrm{M}}, \mathrm{W} 142^{\mathrm{M}}$ and $\mathrm{D} 151^{\mathrm{M}}$ in the viral and D-type cyclins argues that cyclins with these residues bind their cdk partners in a similar manner to M-cyclin. Indeed, models of V-cyclin-cdk6 complex derived from $\mathrm{M}$-cyclin ${ }^{\mathrm{H} 175 \mathrm{R}}-\mathrm{cdk} 2$ appear to be consistent with this proposal (data not shown) but are 
unable to explain why M-cyclin does not bind cdk4 or cdk6. Further experiments guided by the structure described here are required in order to establish that M-cyclin provides an appropriate model for other cyclincdk complexes.

\section{Materials and methods}

\section{Plasmids and antibodies}

The cyclin A construct, a gift from Dr Jonathan Pines, has the human cyclin A gene with a c-myc tag at its $\mathrm{N}$-terminus transcribed from a cytomegalovirus (CMV) promoter. The following plasmids have been described previously: pcDNA3-cyclin D1 and pcDNA3-K cyclin (Mann et al., 1999). The $\gamma \mathrm{HV}-68$ cyclin clone, a gift from Dr William Burns (Wisconsin Medical School), was PCR subcloned into pRSETA (Invitrogen) using oligonucleotides that eliminated the EcoRI site at nucleotide 13 while conserving the amino acid sequence. In a manner identical to the cyclins described above, $\gamma \mathrm{HV}-68$ cyclin was N-terminally tagged by FLAG epitopes introduced by ligating a double-stranded oligonucleotide into the unique $\mathrm{NcoI}$ site in the pRSETA construct. A PCR mutation $\mathrm{H} 175$ to $\mathrm{R}$ gave a mutant M-cyclin, which was characterized in parallel with the wild-type viral cyclin.

For expression in mammalian cells, the tagged cyclin was subcloned into pcDNA3 via BamHI-EcoRI (Invitrogen). These constructs were a generous gift from C.Swanton. The co-immunoprecipitation experiments used the following antibodies: anti-cdk2 SC-163; anti-cdk4 SC-260; anticdk6 SC-177 (Santa Cruz Biochemicals); anti-FLAG (Sigma, M2); and anti-cyclin A (rabbit polyclonal, a gift from Jonathan Pines).

\section{Cell culture, lysis and immunoprecipitation}

The culture and transfection of U2-OS cells have been described previously (Mann and Jones, 1996). Cells were split the day before being transiently transfected with $10 \mu \mathrm{g}$ of mammalian expression constructs encoding cyclins. At $48 \mathrm{~h}$ post-transfection, cells were harvested by scraping cells into $50 \mathrm{mM}$ HEPES $\mathrm{pH} 7.5,150 \mathrm{mM} \mathrm{NaCl}, 1 \mathrm{mM}$ EDTA, $2.5 \mathrm{mM}$ EGTA, $10 \%$ glycerol, $1 \mathrm{mM}$ dithiothreitol (DTT), $0.1 \%$ Tween$20,10 \mathrm{mM} \beta$-glycerophosphate, $0.1 \mathrm{mM}$ phenylmethylsulfonyl fluoride (PMSF). Cell lysates were subject to immunoprecipitation for $2 \mathrm{~h}$ at $4^{\circ} \mathrm{C}$ with anti-FLAG antibodies conjugated to agarose (M2 Affimatrix; Kodak) or with anti-human cyclin A antibodies.

\section{Immunoblotting and in vitro kinase assay}

Immunoprecipitates from three parallel transient transfections were pooled and split into five aliquots. One aliquot was used for immunoblotting. Immunoprecipitates were washed extensively, separated by SDS-PAGE and transferred to Protran (Schleicher and Schuell). Membranes were incubated with antibodies against cdk subunits (anticdk2 SC-163, anti-cdk4 SC-260 and anti-cdk6 SC-177; Santa Cruz Biochemicals) and visualized by ECL (Amersham Pharmacia Biotech). The other four aliquots were used in kinase assays. Immunoprecipitates were resuspended in $30 \mu \mathrm{l}$ of $50 \mathrm{mM}$ HEPES $\mathrm{pH} 7.5,10 \mathrm{mM} \mathrm{MgCl}_{2}$, $1 \mathrm{mM}$ DTT, $2.5 \mathrm{mM}$ EGTA, $10 \mathrm{mM} \beta$-glycerophosphate, $50 \mu \mathrm{M}$ ATP, $10 \mu \mathrm{Ci}$ of $\left[\gamma^{32} \mathrm{P}\right] \mathrm{ATP}(6000 \mathrm{Ci} / \mathrm{mmol})$ and $5 \mu \mathrm{g}$ of purified GST-Rb (C-terminus) as substrate with either $0,0.1,1$ or $10 \mu \mathrm{g}$ of purified $\mathrm{p} 27$. Reactions were incubated for $30 \mathrm{~min}$ at $30^{\circ} \mathrm{C}$ and then loaded on a $10 \%$ SDS-polyacrylamide gel. Gels were dried and analysed by autoradiography and quantitated by phosphoimaging.

\section{Preparation of the M-cyclin-cdk2 complex}

Human cdk2 was produced by a recombinant baculovirus (a gift from Professor D.Morgan, UCSF) used to infect Sf9 insect cells according to published protocols (Rosenblatt et al., 1993). M-cyclin was produced as a GST-tagged fusion protein using the vector pGEX-KG vector (Guan and Dixon, 1991) in a DH5 $\alpha$ bacterial host. Each 11 culture, containing $200 \mathrm{mg}$ of ampicilin, was grown at $37^{\circ} \mathrm{C}$ until an $\mathrm{OD}_{600 \mathrm{~nm}}$ of 0.7 was reached. The temperature was then lowered to $25^{\circ} \mathrm{C}$ until an $\mathrm{OD}_{600 \mathrm{~nm}}$ of 1.3 was attained, whereupon it was lowered further to $18^{\circ} \mathrm{C}$ before overnight induction with $0.025 \mathrm{mM}$ isopropyl- $\beta$-D-thiogalactopyranoside (IPTG). The cells were harvested by centrifugation at $5000 \mathrm{~g}$ for $15 \mathrm{~min}$ at $4{ }^{\circ} \mathrm{C}$, before being resuspended in pre-cooled lysis buffer: $20 \mathrm{mM}$ Tris pH 7.9, $100 \mathrm{ml} \mathrm{NaCl}, 1 \mathrm{mM}$ EDTA, 0.5\% Tergitol NP-40, $10 \mathrm{mM}$ DTT, $10 \mathrm{mM}$ leupeptin, $1 \mathrm{mM}$ pepstatin A, $10 \mathrm{mM}$ benzamidine and $1 \mathrm{mM}$ PMSF. Sonication on ice was followed by centrifugation at $25000 \mathrm{~g}$ for $30 \mathrm{~min}$ at $4^{\circ} \mathrm{C}$, before the supernatant was batch-purified on pre- equilibrated glutathione-Sepharose 4B resin (Pharmacia). Following three washes in lysis buffer and one in PBSA buffer $(1.4 \mathrm{M} \mathrm{NaCl}, 30 \mathrm{mM}$ $\mathrm{KCl}, 100 \mathrm{mM} \mathrm{Na}_{2} \mathrm{HPO}_{4}, 20 \mathrm{mM} \mathrm{NaH}_{2} \mathrm{PO}_{4}, 10 \mathrm{mM}$ DTT), the resin was incubated overnight at $4^{\circ} \mathrm{C}$ with $6 \mathrm{U}$ of thrombin (Boehringer Mannheim), leaving $\mathrm{M}$-cyclin in the soluble fraction. The resin was removed using a PD10 column and any excess thrombin inactivated using inhibitors. The M-cyclin was then concentrated using an Amicon stirred cell, before being loaded onto a Superdex 75 FPLC column (Pharmacia), preequilibrated in running buffer: $50 \mathrm{mM}$ Tris $\mathrm{pH} 7.9,150 \mathrm{mM} \mathrm{NaCl}, 10 \mathrm{mM}$ DTT. M-cyclin was isolated in an elution volume corresponding to a mol. wt of $29000 \mathrm{Da}$, consistent with SDS-PAGE. The identity of M-cyclin was confirmed by mass spectroscopy fingerprinting following limited trypsin digest.

\section{Crystallization of the M-cyclin-cdk2 complex}

The purified human cdk2 and M-cyclin were mixed in an equimolar ratio before being concentrated in an Amicon stirred cell to $20 \mathrm{mg} / \mathrm{ml}$. The complex was purified further on a Superdex 75 FPLC column (Pharmacia), pre-equilibrated in the above running buffer. The M-cyclin-cdk2 complex eluted at a volume corresponding to a mol. wt of $\sim 63000 \mathrm{Da}$. Crystals of the complex grew by vapour diffusion or micro-batch as thin single plates by mixing equal volumes of the complex at $6 \mathrm{mg} / \mathrm{ml}$ with the crystallization buffer; 0.1 M HEPES pH 7.5, $12 \%$ propan-2-ol, 5\% polyethylene glycol 4000 (PEG 4K) and $10 \mathrm{mM}$ DTT. Crystals regularly took only $4 \mathrm{~h}$ to grow at room temperature to dimensions of $\sim 100 \times 100 \times 4 \mu \mathrm{m}$, with the largest reaching $400 \times 500 \times 4 \mu \mathrm{m}$ after 1 day. Crystals were harvested immediately to prevent further nucleation. The crystals tended to grow as multiclustered plates unsuitable for data collection. This was partially overcome by micro- or streak-seeding clear drops after $6 \mathrm{~h}$

\section{Data collection and reduction}

Owing to the thin nature of these crystals, a high intensity X-ray source was required. We collected a native data set on the micro-focus beam line ID13 at the European Synchrotron Research Facility (ESRF) at Grenoble, France. Data were recorded using a MAR Research CCD detector. Owing to the unique set-up of the station, the X-ray beam was collimated to $30 \times 30 \mu \mathrm{m}$, allowing several images to be recorded from a single crystal, which was translated when the diffraction limit fell below $4 \AA$. The data were reduced using the programs DENZO and SCALEPACK (Otwinowski and Minor, 1997). The statistics for the data are shown in Table I. The presence of two M-cyclin-cdk2 complexes per asymmetric unit was established from a self-rotation function and native Patterson synthesis. We note that the M-cyclin-cdk2 complex associates as a noncrystallographic dimer, which is quite different from that observed in three independent crystal forms of cyclin A-cdk2 (Brown et al., 1999). The R $175^{\mathrm{M}}$ mutation places the guanidino group between $\mathrm{F} 179^{\mathrm{M}}$ and $\mathrm{Y} 171^{\mathrm{M}}$, thereby making favourable interactions with the $\pi$ electron clouds from their respective ring systems. It is still unclear how this improves the solubility of recombinant M-cyclin.

\section{Structural determination and refinement}

Initial phases were obtained by molecular replacement after modification of the complex structure of cdk2-cyclin A, PDB ID code 1FIN. The search model for cdk2 was left unaltered, but the cyclin A model was trimmed back to a polyalanine probe model but included side chains from conserved residues identified from sequence alignment $(15 \%$ of all side chains). The program AMoRE (CCP4, 1994) was used to search for the two molecules expected in the asymmetric unit, and two distinct solutions were obtained. The initial phases were improved further by applying 2 -fold non-crystallographic symmetry (NCS) averaging using the programs MAMA and IMP (Jones et al., 1991), and by solvent flattening, histogram matching and phase extension with NCS averaging in the program DM (Cowtan, 1994). Model building was performed using the program O (Jones et al., 1991) and initial refinement carried out using X-PLOR incorporating $R_{\text {free }}$ validation of the progress of refinement (Brünger, 1996). After four cycles of positional refinement and one cycle of simulated annealing, refinement was continued using CNS (Brünger, 1998). The final $R$ and $R_{\text {free }}$ values were 23.5 and $28.5 \%$, respectively, with an r.m.s.d. of $0.0088 \AA$ from ideal bond lengths and $1.41^{\circ}$ for angles. Eighty-four per cent of residues were within the most favourable region of a Ramachandran plot. 


\section{Acknowledgements}

We thank the staff at the ESRF ID13 microfocus beamline for assistance in data collection, in particular Anastassis Perrakis. We also thank Naomi Clout, Gordon Peters, Charlie Swanton and David Mann for helpful discussions throughout this project. G.L.C. is funded by an EU framework IV grant number BIO4-CT96-0285 to N.Q.M. Co-ordinates and structure factors have been deposited in the Protein Databank.

\section{References}

Albrecht,J.C., Nicholas,J., Cameron,K.R., Newman,C., Fleckenstein,B. and Honess,R.W. (1992) Herpesvirus saimiri has a gene specifying a homologue of the cellular membrane glycoprotein CD59. Virology, 190, 527-530.

Andersen,G., Busso,D., Poterszman,A., Hwang,J.R., Wurtz,J.M., Ripp,R., Thierry,J.C., Egly,J.M. and Moras,D. (1997) The structure of cyclin $\mathrm{H}$ : common mode of kinase activation and specific features. EMBO J., 16, 958-967.

Brown,N.R., Noble,M.E., Endicott,J.A., Garman,E.F., Wakatsuki,S., Mitchell,E., Rasmussen,B., Hunt,T. and Johnson,L.N. (1995) The crystal structure of cyclin A. Structure, 3, 1235-1247.

Brown,N.R., Noble,M.E., Endicott,J.A. and Johnson,L.N. (1999) The structural basis for specificity of substrate and recruitment peptides for cyclin-dependent kinases. Nature Cell Biol., 1, 438-443.

Brünger,A.T. (1996) X-PLOR Reference Manual 3.851. Yale University, New Haven, CT.

Brünger,A. (1998) Crystallography and NMR system: a new software suite for macromolecular structure determination. Acta Crystallogr. D, 54, 905-921.

CCP4 (1994) The CCP4 suite: programs for computational crystallography. Acta Crystallogr. D, 50, 760-763.

Chang,Y., Moore,P.S., Talbot,S.J., Boshoff,C.H., Zarkowska,T., Godden,K., Paterson,H., Weiss,R.A. and Mittnacht,S. (1996) Cyclin encoded by KS herpesvirus. Nature, 382, 410.

Cowtan,K. (1994) DM: an automated procedure for phase improvement by density modification. Joint CCP4/ESF-EACBM newsletter. Protein Crystallogr., 31, 34-38.

Ellis,M., Chew,Y.P., Fallis,L., Freddersdorf,S., Boshoff,C., Weiss,R.A., Lu,X. and Mittnacht,S. (1999) Degradation of p27(Kip) cdk inhibitor triggered by Kaposi's sarcoma virus cyclin-cdk6 complex. EMBO J., 18, 644-653.

Godden-Kent,D., Talbot,S.J., Boshoff,C., Chang,Y., Moore,P., Weiss,R.A. and Mittnacht,S. (1997) The cyclin encoded by Kaposi's sarcoma-associated herpesvirus stimulates cdk6 to phosphorylate the retinoblastoma protein and histone H1. J. Virol., 71, 4193-4198.

Guan,K. and Dixon,J.E. (1991) Eukaryotic proteins expressed in Escherichia coli: an improved thrombin cleavage and purification procedure of fusion proteins with glutathione $S$-transferase. Anal. Biochem., 192, 262-267.

Jeffrey,P.D., Russo,A.A., Polyak,K., Gibbs,E., Hurwitz,J., Massague,J. and Pavletich,N.P. (1995) Mechanism of CDK activation revealed by the structure of a cyclinA-CDK2 complex. Nature, 376, 313-320.

Jones,T.A., Zou,J.Y., Cowan,S.W. and Kjeldgaard,M. (1991) Improved methods for building protein models in electron density maps and location of errors in these models. Acta Crystallogr. A, 47, 110-119.

Jung,J.U., Stager,M. and Desrosiers,R.C. (1994) Virus-encoded cyclin. Mol. Cell. Biol., 14, 7235-7244.

Kato,J., Matsushime,H., Hiebert,S.W., Ewen,M.E. and Sherr,C.J. (1993) Direct binding of cyclin $\mathrm{D}$ to the retinoblastoma gene product $(\mathrm{pRb})$ and $\mathrm{pRb}$ phosphorylation by the cyclin D-dependent kinase CDK4. Genes Dev., 7, 331-342.

Kim,K.K., Chamberlin,H.M., Morgan,D.O. and Kim,S.H. (1996) Threedimensional structure of human cyclin $\mathrm{H}$, a positive regulator of the CDK-activating kinase. Nature Struct. Biol., 3, 849-855.

Laman,H., Mann,D.J. and Jones,N.C. (2000) Viral-encoded cyclins. Curr. Opin. Genet. Dev., 10, 70-74.

Li,M., Lee,H., Yoon,D.W., Albrecht,J.C., Fleckenstein,B., Neipel,F. and Jung,J.U. (1997) Kaposi's sarcoma-associated herpesvirus encodes a functional cyclin. J. Virol., 71, 1984-1991.

Mann,D.J. and Jones,N. (1996) E2f-1 but not E2f-4 can overcome p16induced $\mathrm{G}_{1}$ cell-cycle arrest. Curr. Biol., 6, 474-483.

Mann,D.J., Child,E.S., Swanton,C., Laman,H. and Jones,N. (1999) Modulation of p27(Kip1) levels by the cyclin encoded by Kaposi's sarcoma-associated herpesvirus. EMBO J., 18, 654-663.
Morgan,D.O. (1995) Principles of CDK regulation. Nature, 374, 131134.

Morgan,D.O. (1997) Cyclin-dependent kinases: engines, clocks and microprocessors. Annu. Rev. Cell Dev. Biol., 13, 261-291.

Otwinowski,Z. and Minor,W. (1997) Processing of X-ray diffraction data collected in oscillation mode. Methods Enzymol., 276, 307-326.

Palmero,I. and Peters,G. (1996) Perturbation of cell cycle regulators in human cancer. Cancer Surv., 27, 351-367.

Pines,J. (1999) Four-dimensional control of the cell cycle. Nature Cell Biol., 1, E73-E79.

Rosenblatt,J., DeBondt,H., Jancarik,J., Morgan,D.O. and Kim,S.H. (1993) Purification and crystallisation of human cyclin-dependent kinase 2. J. Mol. Biol., 230, 1317-1319.

Russo,J.J. et al. (1996a) Nucleotide sequence of the Kaposi sarcomaassociated herpesvirus (HHV8). Proc. Natl Acad. Sci. USA, 93, $14862-14867$.

Russo,A.A., Jeffrey,P.D. and Pavletich,N.P. (1996b) Structural basis of cyclin-dependent kinase activation by phosphorylation. Nature Struct. Biol., 3, 696-700.

Russo,A.A., Jeffrey,P.D., Patten,A.K., Massague,J. and Pavletich,N.P. (1996c) Crystal structure of the p27Kip1 cyclin-dependent-kinase inhibitor bound to the cyclin A-Cdk2 complex. Nature, 382, 325-331.

Schulze-Gahmen,U., Jung,J.U. and Kim,S.H. (1999) Crystal structure of a viral cyclin, a positive regulator of cyclin-dependent kinase 6 . Structure Fold Des., 7, 245-254.

Sherr,C.J. (1994) $\mathrm{G}_{1}$ phase progression: cycling on cue. Cell, 79, 551555.

Sherr,C.J. (1995) D-type cyclins. Trends Biochem. Sci., 20, 187-190.

Sherr,C.J. (1996) Cancer cell cycles. Science, 274, 1672-1677.

Sherr,C.J. and Roberts,J.M. (1999) CDK inhibitors: positive and negative regulators of $\mathrm{G}_{1}$-phase progression. Genes Dev., 13, 15011512.

Swanton,C., Mann,D.J., Fleckenstein,B., Neipel,F., Peters,G. and Jones,N. (1997) Herpes viral cyclin-Cdk6 complexes evade inhibition by CDK inhibitor proteins. Nature, 390, 184-187.

Swanton,C., Card,G.L., Mann,D., McDonald,N.Q. and Jones,N. (1999) Overcoming inhibitions: viral cyclin subversion of CKI function. Trends Biochem. Sci., 24, 116-120.

Taylor,W.R. and Orengo,C.A. (1989) Protein structure alignment. J. Mol. Biol., 208, 1-22.

van Dyk,L.F., Hess,J.L., Katz,J.D., Jacoby,M., Speck,S.H. and Virgin,H.I. (1999) The murine $\gamma$-herpesvirus $68 \mathrm{v}$-cyclin gene is an oncogene that promotes cell cycle progression in primary lymphocytes. J. Virol., 73, 5110-5122.

Virgin,H.W.,IV, Latreille,P., Wamsley,P., Hallsworth,K., Weck,K.E., Dal Canto,A.J. and Speck,S.H. (1997) Complete sequence and genomic analysis of murine $\gamma$-herpesvirus 68. J. Virol., 71, 58945904.

Received March 10, 2000; revised and accepted April 20, 2000 